\title{
sciendo
}

DOI 10.2478/sbe-2020-0002

SBE no. 15(1) 2020

\section{THE LABOUR MARKET CRISIS IN ROMANIA CAUSES, EFFECTS AND POTENTIAL SOLUTIONS}

\author{
CINDREA IOAN \\ Lucian Blaga University of Sibiu, Romania
}

\begin{abstract}
:
We are going through troubled times, with worldwide pandemic crises affecting us altogether: citizens, companies and states. This article presents analyses and solutions to the workforce crisis of December 2019 and the workplace crisis of March 2020. Things have escalated from a workforce crisis to a new stage, namely an accelerated loss of workplaces and to a workplace crisis. In a matter of weeks, the labour market has moved from one extreme to the other extremely fast because of a very rough natural phenomenon which could not have been predicted, i.e. the global pandemic crisis caused by the COVID-19 coronavirus. It goes without saying that we all wish to achieve a relative balance on the labour market. This study puts forward concrete solutions adapted to the situation of the Romanian labour market at the end of 2019, when we saw a significant workforce crisis which severely affected companies' business development objectives. At the same time, it introduces 11 solutions to the new job crisis, which is quickly expanding as a result of the global pandemic caused by the COVID-19 virus and by the declaration of a state of emergency in Romania. In a few weeks of crisis, Romania went from minus 1 million workers to plus 1 million workers. This is an extremely difficult situation. However, I believe that it is temporary and that after the pandemic crisis both the economy and the labour market will gradually recover.
\end{abstract}

Key words: crisis, workforce, workplaces, labour market balance, alternative solutions

\section{Introduction}

Nowadays, we are facing such high-amplitude social and economic phenomena, with major effects that humankind has never seen before, all of these caused by COVID-19, a virus which has triggered a global pandemic crisis. At the end of 2019, I started analysing and documenting an extensive article on the labour market crisis in Romania.

Romania was going through an acute workforce crisis, which questioned the future development of the country and endangered the fulfilment of companies' business objectives. They all felt the impact of this acute workforce crisis. All managers stated that their companies' business objectives were threatened by the workforce shortage. 
Studies (Quantitative and Qualitative Labour Market Analysis in Romania, conducted by KPNG and by the Romanian Academy's National Institute of Business Research - INCE, commissioned by the Concordia Employers Confederation) showed that Romania urgently needed at least 308,000 workers in 2019 , and that this number would increase to over half a million individuals. Some studies showed that the actual number of workers needed in Romania was close to one million.

My study was complete, including causes, effects and potential solutions. It was under translation and drafting when this COVID-19 global pandemic happened and unfortunately Mother Nature, tough and unforgiving in its objective, unwritten laws, radically turned the natural conditions with hugely devastating effects for the economy.

This led to the beginning of the economic crisis and the context of the Romanian labour market drastically changed. In a matter of weeks, we went from a workforce crisis to a severe and unsettling workplace and unemployment crisis. The labour market thereby moved from one extreme to the other in a couple of days.

On March $11^{\text {th }}$, 2020, the World Health Organization (WHO) declared a global pandemic generated by the infection with the COVID-19 virus. The effects expand, affecting Europe and then quickly all states, including Romania. On March $16^{\text {th }}, 2020$, as a result of the infection with the COVID-19 virus, the President of Romania issued the Decree on the State of Emergency in Romania.

From this point forward, things rapidly escalated to closing and significantly restricting certain businesses affected directly or indirectly. This has led and further leads, for we are in the middle of this situation, to the disappearance of numerous workplaces. In March 2020, when this analysis was carried out, over 200,000 workplaces closed, with a grim perspective of reaching as much as 1 million workplaces lost in the upcoming days, according to the latest forecasts.

From the urgent need of 1 million new workers in December 2019, now, 2 months and 24 days later, we are facing the possibility of reaching to 1 million unemployed.

The situation has evolved from a workforce crisis to a shortage of workplaces. Within three months, we recorded a difference of 2 million lost workplaces. This is why I entitled this article that tackles the two extremes with severe economic and social effects 'The Labour Market Crisis in Romania'.

Obviously, the situation is now much worse and more difficult. The workplace shortage leads to unemployment and brings an entire chain of underlying social issues. I analysed potential solutions, both for the present and for the future.

Under these circumstances, I still wanted to maintain and present the part of my December 2019 study on the labour market crisis in Romania, covering the causes, effects and potential solutions. I want and I believe it should be published for similar situations that may arise and that we might face in the future. In the end, I also included several state intervention solutions which could and should have been taken in these circumstances. I believe that this December 2019 analysis can enrich scientific literature with potential solutions to similar situations occurring in the future.

Moreover, I present the main solutions that the Government and companies must take in order to limit unemployment in Romania and to preserve existing workplaces. 


\section{The workforce crisis - December 2019}

The causes of the workforce crisis at the end of 2019 were especially the extended migration of the workforce to more financially attractive zones of Europe (estimated to 3 million people), the severe, pronounced demographic decline registered in 1990-2019 assessed to over 1 million people, and the social marginalization of a significant part of the population remaining in the country, considering that the youth employment rate is $50 \%$ (47\% in 2018), according to the KPNG and INCE study of the Romanian Academy, 'The Quantitative and Qualitative Analysis of the Labour Market in Romania'.

Under these circumstances of workforce crisis, the lack of reaction from the state, through its institutions, raises concern. There has been no serious analysis, nor actions to limit or to stop the workforce crisis, or to find valid solutions for the future. The passivity of those who, by Constitution and by law, are obliged to act and intervene, is inconceivable and unacceptable. This is a major national interest, with strong implications for the sustainable development of Romania.

Investments and investors are not attracted to and do not come to a country lacking the most important resource, namely the human resource. Nobody invests in an area/country where there is a workforce deficit, as such an investment is destined to fail from the very beginning. The workforce, the people are the ones driving the other resources of a business and ensuring its viability. The workforce shortage, the lack of people, will inevitably lead to economic standstill and even more seriously to recession and finally to economic and social crisis, with all the serious effects that come with it.

The theory that objective economic laws can solve the situation on the labour market through the objective mechanisms of supply and demand cannot be viable. We need the state to intervene strongly, quickly and with determination to ensure balanced workforce supply and demand in Romania.

Below, we would like to present some of the most important state intervention leverages and mechanisms aimed at restoring labour market balance (valid in December 2019).

Of course, we could not cover all the solutions so the list stays open to institutional authorities, social experts and partners, employers' associations and trade unions.

1. Amending public policies regarding the Romanian labour market to adapt to the workforce crisis conditions. In the sense of incentivizing employment, not income support/staying home. This will also lead to a higher employment rate in Romania. We estimated that, out of the 170,303 income support beneficiaries in Romania in December 2019, at least one third, i.e. 65,000 individuals, are people of working age, fit to work and that, after professional training and short-term qualification courses, they can be activated in areas such as: construction, agriculture, tourism or other unqualified labour. (Source: Ministry of Labour and Social Protection National Agency for Payments and Social Inspection' 'Report on income support/minimum guaranteed income, reporting month December 2019')

2. Extensive national programmes must be implemented to provide professional training to employees via companies and to the unemployed via the National Agency for Employment. These programmes will adapt the workforce to the new 
requirements on the labour market. In this regard, we must attract funds to support the professional training of adult human resources through a national programme with company resources, supplemented by funding and resources from the unemployment budget, as well as from the European Union budget. During this EU financial framework, the Operational Programme Human Capital (OPHC), the former 2007-2013 financial framework's Sectoral Operational Programme Human Resources Development (SOP HRD), plays an important role in supporting the financing of professional training. The funding lines open until the first quarter of 2020 in Romania for OPHC amount to a total of EUR 4.66 billion, representing $91.5 \%$ of the amount allocated for this programme in our country (Source: Ministry of European Funds, public website). The important thing is for Romania to attract and use this amount of money and to achieve the forecasted positive effects on the labour market, both quantitatively, in terms of employment rate, and qualitatively, in terms of the professional training of Romanian workers.

3. Adapting the school and university network to the actual Romanian workforce requirements, both quantitatively and relative to qualitative training. The graduates must have a profession/specialization that is required on the labour market and hold the knowledge level required by available current workplaces. For years now, attempts have been made to adapt academic figures to the actual requirements of the labour market. However, for various reasons, this was not achieved except for a formal 'cosmetic reworking' of the school network. To achieve this social objective of utmost importance, substantial changes are necessary.

4. Guiding young people towards professions/specializations for which they hold skills. Career guidance must be done professionally and scientifically, not empirically, as it unfortunately happens today. The goal of career guidance should be: the right person for the job or specialization for which they hold the required skills. It is vital, both for society, and for all individuals to be guided and trained for professions which are suitable to them. This involves significant social and individual costs!

5. Ensuring a public policy on Romanian public income. The tools to provide fair balance from a social point of view are:

- Minimum consumer basket

- Minimum gross wage to be paid

- Maximum wage in the public sector

- Minimum pension

- Maximum pension

- Level of the minimum guaranteed income support

- Income template and level of taxation - as an important tool for cost adjustment.

An optimum and fair ratio must be established between these state tools, ensuring a minimum decent standard of living for millions of people, starting from the actual level of the minimum consumption basket.

The implications are extremely important to ensure social equality and stability. 
A fair public policy for income and its taxation in Romania could ensure financial balance. At the same time, this will also have significant effects on the pay scale in the private sector.

Obviously, we only presented 5 major lines of action to ensure balance on the Romanian labour market.

Each of these requires careful analysis and the drafting of a new legislative and institutional framework.

Of course, the list remains open!

\section{The workforce crisis - April 2020}

I believe that under the current situation as well, determined by the global pandemic caused by COVID-19 coronavirus, all the afore-mentioned proposals remain valid and applicable for a functional labour market in Romania.

Before concluding this study, I would like to come back to the present, when we have quickly moved into a workplace crisis, as jobs are threatened or affected by the COVID-19 crisis.

All analyses indicate that this is an unprecedented exceptional situation. However, we tend to believe this is a temporary crisis and that after the pandemic the economy can recover in a relatively short timeframe.

Under these circumstances of a medical crisis which, according to some medical experts, is to end at the end of May - the beginning of June, we believe the main concern of companies is to retain their employees. They are the most important resource and should be retained at any cost. Once they leave, it will be more difficult to find others adapted to those workplaces. Starting from this fact, we think that there are at least 11 very important solutions to which employers, both large and small companies, should resort.

Here are the 11 alternative solutions to retain employees until business resumes, presumably in May-June 2020:

\section{Working from home}

Working from home is applicable to all situations in which the worker can work from their declared residence. This requires an addendum to the individual labour contract to be signed, jointly negotiated with the employee. Obviously, the employment relationship continues, but new terms may be added, such as: supplying the new workplace, transporting the products, additional costs borne by the employer (energy, electricity, gas, etc.), new pay scales, etc. The employer pays the wage and covers possible new additional costs.

\section{Teleworking}

One can identify those workplaces and employees who can work at home, using information and communication technology. In this case too, an addendum to the employee's individual labour contract will be negotiated. Additional terms can be negotiated. The employer will pay the employee and reimburse any possible negotiated additional costs arising as a result of moving the workplace to the employee's residence. 


\section{Technical unemployment}

Only employees whose activity cannot be carried out under other conditions (teleworking, work from home, etc.) will be placed into technical unemployment. They are unable to work as a result of direct/indirect effects of the epidemic generated by COVID-19. Technical unemployment can be granted throughout the state of emergency in Romania. Employment relationships are suspended and, during the technical unemployment, an allowance amounting to $75 \%$ of the gross salary is paid, according to art. 53 of the Labour Code, but no more than $75 \%$ of the gross average salary stipulated in Law no. 6/2020 on 2020 the Social Insurance Budget, namely RON 5,429. The maximum amount is RON 4,072. It shall be paid by the company from the Unemployment Budget, via the County Employment Agencies which will transfer the amounts within 15 days, upon the company's request.

\section{Annual leave}

Annual leave is only granted upon the employee's request, with the employer's approval. Annual leave can also be taken in advance, with the company's (employer's) approval. In this case, the employer pays the annual leave allowance stipulated by law.

\section{Unpaid leave}

Unpaid leave is only granted upon the employee's request, with the employer's approval. The employer cannot request unpaid leave for the employee. During the unpaid leave, the employee does not receive their salary and the individual labour agreement is suspended. Should the employee exceed 3 months of no-income, they will no longer benefit from medical insurance.

\section{Professional training leave}

Professional training leave is granted according to art. 154-158 of the Labour Code and can be granted by paying the salary or not, as applicable.

\section{Paid days off for overtime}

Paid days off to be granted to only one parent for the supervision of children under the age of 12, or 18 in the case of children with disabilities

This solution may only be used if the employee's workplace does not allow telework or work from home. The employer will pay an allowance amounting to $75 \%$ of the basic salary, but no more than $75 \%$ of the gross average salary. This allowance will be paid by the employer and fully reimbursed to the employer from the state budget.

\section{Reduced working hours}

Reduced working hours and reduced basic salary is only possible upon individual negotiation and with the employee's consent. 
Reduced work schedule from 5 days/week to 4 days/week

In this case, the basic salary is also consequently reduced. It can be implemented upon the employer's initiative. It is applicable for a period of more than 30 days.

\section{Quarantine sick leave}

Quarantine sick leave is granted to employees who, for medical reasons, are recommended to quarantine following an infection or suspected infection with COVID-19. The employees receive an allowance amounting to $75 \%$ of the gross average salary earned in the last 6 months. They benefit from this protection as beneficiaries of the public health insurance system. The allowance will be paid by the employer and will be reimbursed from the Single Health Insurance Fund through the County Health Insurance Departments.

Note that we have a legal framework for granting each one of these allowances.

The aim of each company is or should be to retain its employees and implicitly to ensure the revenue necessary for this period until business can be resumed. As a last resort, after exhausting the above-mentioned solutions, companies may terminate the individual labour agreements for reasons not attributable to the employee. In this situation, the position is eliminated. The reason should be real and serious, and this decision must be recorded in an internal decision. Prior to redundancy, the procedure set forth in the labour legislation through the Labour Code stipulates that the company will offer the employee other vacant positions in the company compatible with their professional background and experience, provided that such positions exist.

When there is no such compatible position for the employee, the company will grant a minimum of 20 days' notice (or according to the individual labour agreement, if a more extensive notice was agreed).

Note that the employee whose individual labour agreement was terminated in this way (for reasons not attributable to the employee) will receive unemployment benefits.

All the above-mentioned solutions aimed at retaining employees are supplemented by the extremely important governmental measures aimed at supporting companies directly and indirectly affected by the crisis, as well as by further financial support measures to resume the business of companies when the state of emergency ceases.

\section{Conclusions}

In this paper, I presented the method of analysis and approach of the two extreme situations on the labour market: the December 2019 workforce crisis and the April 2020 job crisis. For each of these situations, I also included institutional and legislative intervention solutions that the state may take considering its corresponding constitutional role.

Certainly, the list of solutions is and remains open in both cases. I think it is worth noting that the state, through its institutions, social partners, employers' associations, companies and employees must work together and intervene in order to limit these crisis situations and to ensure relatively balanced workforce supply and demand. This is both a duty and a necessity, since we are talking about people and companies as active social 
partners in the economy. The labour market is only functional if social partners, employees and employers work together and if the state becomes an active part of this process. For the Romanian labour market to work, we need laws, institutions and mechanisms to ensure the negotiation, regulation and resolution of conflicts.

In conclusion, we will have a working labour market if these are available and work properly. This is a major objective. This paper describes a few limits and solutions to apply in both crisis situations under analysis. Hopefully, this paper should be a modest contribution to human resource management literature and practice, at both company and national level.

\section{References}

Cindrea, I. (2006). Labour Market Management, Publishing House of the "Lucian Blaga" University of Sibiu

Cindrea, I. (2018). Human Resource Management. Second edition., Publishing House of the "Lucian Blaga" University of Sibiu

Cole, G. A. (1988). Personnel Management: Theory and Practice. $2^{\text {nd }}$ edition. The Guernsey Press Company Ltd. London

Ogrean, C. (2007). Strategic Management, Publishing House of the "Lucian Blaga" University of Sibiu

Petrescu, I., Cindrea, I. (1998). Theory and Practice of Human Resource Management, Lux Libra Publishing House, Brasov

Petrescu, I. (2003). Organization Personnel Management, Expert Publishing House, Bucharest

Popescu, D. (2018). Turbulent Times: The Fascinating Ignored History, Continent Publishing House

KPNG, National Institute of Business Research (INCE), Romanian Academy. Quantitative and Qualitative Labour Market Analysis in Romania

Law no. 53/2003. Updated Labour Code

Updated Romanian legislation on labour and social security

Official statistics by the Government of Romania, the National Statistics Institute and subordinated government institutions 